\title{
The effects of amygdaloid lesions on a classically conditioned auditory discrimination in the rabbit
} (Oryctalagus cuniculus)*

\author{
ERNEST D. KEMBLE, University of Minnesota, Morris, Minn. 56267 \\ JOYCE MONTEAU ALBIN, University of Rochester, Rochester, N.Y. 14627 \\ and \\ DALE W. LEONARD, Purdue University, Lafayette, Ind. 47907
}

The performance of rabbits (Oryctolagus cuniculus) sustaining amygdaloid lesions was compared to that of cortrol Ss during the acquisition of a classically conditioned auditory discrimination. Amygdala damaged Ss showed a reliable $(p<.05)$ elevation in the percentage of nictitating membrane CRs to the CS+ and a marginally significant $(p<.10)$ elevation in CRs to the CS- The lesion effects are discussed in terms of response inhibitory mechanisms or changes in shock-produced arousal. Additional experiments are suggested.

Investigations of amygdaloid function have led various experimenters to suggest a role for this structure in attention (Douglas \& Pribram, 1966), some form of response inhibition (Schwartzbaum, Thompson, \& Kellicutt, 1964; Ursin, 1965; Kemble \& Beckman, 1970), fear-motivated learning (Goddard, 1964 ), and recognition of identification of reinforcing stimuli (Weiskrantz, 1956). Often, however, the data which have led to these suggestions have been obtained in testing situations requiring sequences of molar responses (e.g., Goddard, 1964; Horvath, 1963; Ursin, 1965) which may themselves be altered by amygdaloid intervention (Norton, 1970). Such testing situations also frequently allow for considerable variation in S's orientation to "relevant" stimuli and may also provide several sources of extraneous stimuli. The present experiments were undertaken to explore the usefulness of the classically conditioned nictitating membrane response in investigations of amygdaloid function. It was felt that the relatively precise control of stimulus presentation (and S's orientation toward it) made possible by classical conditioning technique as well as the more molecular nictitating membrane response might make this a valuable research tool for the functional analysis of particular brain structures. SUBJECTS

The Ss were 18 albino New Zealand rabbits (Oryctolagus cuniculus) obtained from a local supplier and ranging from 5 to $6 \mathrm{lb}$ in weight

*This research was supported by an NIMH postdoctoral fellowship to E.D.K.

\section{APPARATUS AND PROCEDURE}

The apparatus was identical to that described in previous work (e.g., Ison $\&$ Leonard, 1971). Briefly, Ss were run four at a time in separate sound-attenuation chambers ( Scientific Prototype, Model SPC-300), with gross body movements restricted by a restraining box. The CS was a $300-\mathrm{msec}$ pure tone which raised the sound level in the chamber to $83 \mathrm{~dB}$ over a $70-\mathrm{dB}$ background of white noise (re: .0002 dynes $/ \mathrm{cm}^{2}$ ). The US was a 50 -msec $10-\mathrm{mA}$ spike of electric shock generated by a Grass stimulator (Model S-4) and delivered circumorbitally to S's right eye. On reinforced trials, the shock overlapped the last $50 \mathrm{msec}$ of a $500-\mathrm{Hz}$ tone. On nonreinforced trials, a $1,500-\mathrm{Hz}$ tone was presented for $300 \mathrm{msec}$ without shock. Intertrial interval varied between 45 and 60 sec. Classical discrimination training was carried out in a single 4.5-5 h session, consisting of 160 reinforced (CS) and 160 nonreinforced (CS) presentations delivered in a repeating RNRRRNNRRNNN sequence.

Nine Ss were originally included in each of the lesioned (amygdaloid) and nonlesioned (control) groups. Two Ss in the lesioned group exhibited behavioral abnormalities following surgery, as described below, and were dropped from the experiment. All surgery was conducted under clean conditions, using IV pentobarbital anesthesia supplemented by local application of Xylocaine. Amygdaloid lesions were placed stereotactically with the aid of a rabbit head-holder (David Kopf Instruments Co.) and with the surface of the skull horizontal. Two lesions were placed on each side of the brain at 0.5 and $1.5 \mathrm{~mm}$ anterior to the bregma, $4.5 \mathrm{~mm}$ lateral to the midline, and $19.0 \mathrm{~mm}$ ventral to the skull surface. The lesions were produced by passing $3.0 \mathrm{~mA}$ anodal dc through the uninsulated tip (approximately $0.5 \mathrm{~mm}$ ) of a stainless steel pin (No. 4, Clay-Adams) for $12.5 \mathrm{sec}$ at each placement. Two of the control Ss received the same surgical treatment as amygdaloid Ss, except for current passage. All operated Ss were allowed to recover for at least 10 days before discrimination training was begun.

At the conclusion of training, amygdaloid Ss were perfused with isotonic saline followed by $10 \%$ formalin solution while deeply anesthetized. After removal and additional hardening, the brains were frozen and sectioned at 24 microns in the coronal plane. Every fifth section through the lesion area was retained and stained with cresyl violet for histological examination.

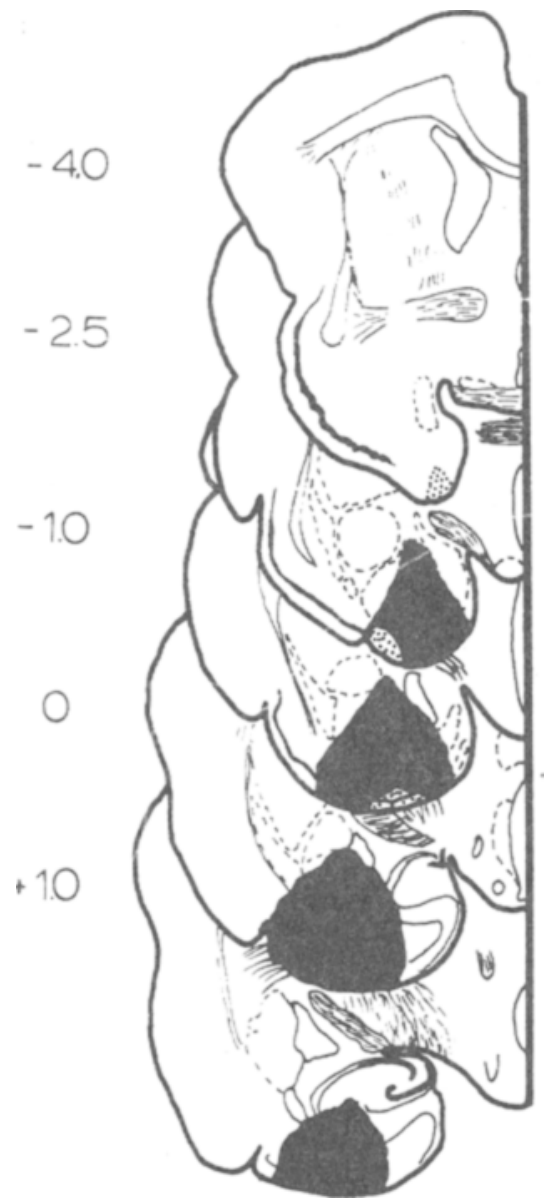

Fig. 1. Reconstruction of the bilateral extent of the largest (black area) and smallest (stippled area) amygdaloid lesions. The largest lesion at -2.5 and -1.0 also includes the stippled area. 


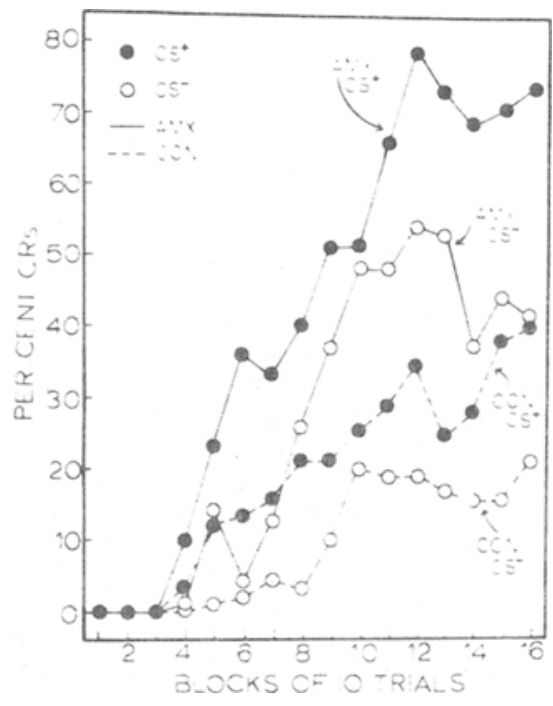

Fig. 2. Percent CRs to CS+ and CSby amygdaloid and control Ss.

\section{HISTOLOGY}

Reconstructions of the bilateral extent of the largest and smallest amygdaloid lesions of the seven Ss whose data is included in this experiment are presented in Fig. 1 on plates redrawn from the atlas of Bures, Petrán, \& Zachar (1967). The lesions were commonly restricted to the medial portions of the amygdala in the region of the medial, cortical, and mediobasal amygdaloid nuclei. Only the largest lesion included substantial damage to the lateral portions of the amygdala. All lesions included damage to the pyriform cortex, and slight bilateral damage to the hippocampus was noted in three Ss. There was no obvious relationship between lesion size, placement, or inclusion of hippocampal damage, and performance. Also, the control operations had no discernible effect on discrimination performance.

Two amygdaloid Ss were excluded from this study before training. One $S$ sustained a bilateral lesion quite similar in size and placement to the largest lesion shown in Fig. 1 but began to show almost continuous seizures 2-3 days postoperatively. Another S sustained a lesion which included damage to dorsal portions of the amygdala and slight damage to the internal capsule. Although there was no apparent damage to the lateral hypothalamus, this animal was aphagic and adipsic following surgery and steadily lost weight until he was sacrificed 5 days postoperatively. We have also occasionally noticed this phenomenon in rats whose amygdaloid lesions extended dorsally.

RESULTS AND DISCUSSION

The results of this experiment are summarized in Fig. 2. It may be seen that Ss sustaining amygdaloid lesions showed increased responding to both the $\mathrm{CS}+$ and $\mathrm{CS}-$ during training. Analysis of performance during the last 50 training trials indicated that amygdaloid Ss made significantly more $\mathrm{CRs}$ to the CS+ than did control Ss $(\mathrm{U}=10, \mathrm{df}=7 / 9, \mathrm{p}<.05)$. Amygdaloid CRs to the CS-, however, were only marginally elevated with respect to control performance $(\mathrm{U}=13, \mathrm{df}=7 / 9, .05<\mathrm{p}<.10)$.

Two possible explanations for the increased levels of response to CS+ and CS- by amygdaloid Ss suggest themselves. One obvious possibility is that amygdaloid lesions produce a disinhibition of response mechanisms similar to that observed following septal area lesions (e.g., McCleary, 1961). Indeed, one of the most frequently documented effects of amygdaloid lesions is a difficulty in withholding or modulating responses in a variety of experimental situations (e.g., Schwartzbaum, Thompson, \& Kellicutt, 1964; Bagshaw \& Pribram, 1968; Kemble \& Beckman, 1970).

It is also possible, however, that the increased responding of amygdaloid Ss in this experiment reflected a heightened level of arousal produced by the electric shock US. Bagshaw \& Pribram (1968) have shown that the GSR threshold to electric shock is lower in amygdalectomized monkeys and that they fail to respond differentially to different shock intensities. In this respect, it should be noted that the lesioned Ss had no apparent difficulty relative to control Ss in developing the discrimination; this suggests that some inhibitory capabilities remain intact in these Ss, along with the ability to process and differentiate stimuli. While this would seem to favor the latter interpretation, it is clear that more data involving response inhibition are needed in situations involving both positive and negative USs. For example, it would be interesting to know whether or not a similar facilitation in response rate would occur using the conditioned jaw-movement response to a sucrose US, a preparation recently developed by Gormezano and his associates (Smith, DiLollo, \& Gormezano, 1966). Such data might be of value in determining whether the effects of amygdaloid lesions are restricted simply to situations employing noxious stimuli and the accompanying high level of arousal inherent in such situations.

All in all, however, the rather dramatic and consistent behavior effect of the amygdaloid lesions in this experiment would seem to indicate that this conditioning preparation holds promise as a tool for examining amygdaloid function. Similar analysis of other limbic structures (e.g., cingulate cortex, hippocampus, septal area) may be of value in delineating similarities and differences of limbic system function.

\section{REFERENCES}

BAGSHAW, M. H., \& PRIBRAM, J. D. Effect of amygdalectomy on stimulus threshold of the monkey. Experimental Neurology, 1968, 20, 197-202.

BURES, J., PETRÁN, M., \& ZACHAR, J. Electrophysiological methods in biological research. (3rd ed.) New York: Academic Press, 1967

DOUGLAS, R. J., \& PRIBRAM, K. H. Learning and limbic lesions. Neuropsychologia, 1966, 4, 197-220.

GODDARD, G. V. Amygdaloid stimulation and learning in the rat. Journal of Comparative \& Physiological Psychology, $1964,58,23-30$.

HORVATH, F. E. Effects of basolateral amygdalectomy on three types of avoidance behavior in cats. Journal of Comparative \& Physiological Psychology, $1963,56,380-389$.

ISON, J. R., \& LEONARD, D. W. Effects of auditory stimuli on the nictitating membrane reflex of the rabbit (Oryctolagus criniculus). Joumal of Comparative \& Physiological Psychology, $1971,75,157-164$.

KEMBLE, E, D. \& BECKMAN, G. J. Runway performance of rats following amygdaloid lesions. Physiology \& Behavior, $1970,5,45-47$.

MCCLEARY, R. A. Response specificity in the behavioral effects of limbic system lesions in the cat. Journal of Comparative \& Physiological Psychology, 1961, 54, 605-613.

NORTON, S. Photographic analysis of rat behavior before and after amygdaloid lesions. Brain Research, 1970,18 477-490.

SCHWARTZBAUM, J. S., THOMPSON, J B. \& KELLICUTT, M. H. Auditory frequency discrimination and generalization following lesions of the amygdaloid area in rats. Journal of Comparative \& Physiological Psychology, $1964,57,257-266$.

SMITH, M. C., Dilollo, V., \& GORMEZANO, 1. Conditioned jaw movement in the rabbit. Journal of Comparative \& Physiological Psychology, $1966,62,479-483$

URSIN, H. Effect of amygdaloid lesions on avoidance behavior and visual discrimination in cats. Experimental Neurology, 1965, 11, 298-317.

WEISKRANTZ, L. Behavioral changes associated with ablation of the amygdaloid complex in monk eys. Journal of Comparative \& Physiological Psychology, 1956, 49, 381-391. 